\title{
Real-time Bus Rollover Prediction Algorithm with Road Bank Angle Estimation
}

\author{
Yu Guizhen, Li Honggang, Wang Pengcheng, Wu Xinkai*, Yunpeng Wang \\ School of Transportation Science and Engineering, Beihang University, Beijing, 100191, \\ China
}

\begin{abstract}
The bus rollover warning has achieved many progresses for researcher endeavors in the past decades. But these researches have not taken account for dynamic road bank. To fill up the gap, this paper presents a real-time rollover trend prediction to indicate bus rollover risk with road bank estimation. The prediction algorithm consists of a dynamic roll stability analysis, which is based on a suspended roll plane model, and a real-time warning velocity calculation. An estimator for the dynamic road bank and vehicle sideslip angle estimation using the dynamic simplex algorithm (DSA) is designed to take into account the influence of road bank on rollover trend. By comparing maximum stable lateral acceleration to the affordable lateral acceleration depending on the tire/road friction limit, a warning velocity is determined using the measurement of lateral acceleration and the estimate of instantaneous vehicle turning radius. The proposed rollover trend prediction algorithm is evaluated by TruckSim software. Simulation results show that the proposed warning velocity can represent the vehicle potential to resist rollover and give appropriate prediction of vehicle rollover crashes in typical scenarios.
\end{abstract}

Keywords: rollover, roll stability, dynamic road bank estimation, dynamic simplex algorithm

\footnotetext{
${ }^{*}$ Corresponding author.

Email address: xinkaiwubuaa@gmail.com (Wu Xinkai)
} 


\section{Introduction}

Now, road safety has caught more and more attention. Among all types of fatalities, vehicle rollover is the most serious one [1]. Previous investigation showed that nearly $33 \%$ of all deaths in passenger vehicle crashes are caused by rollovers [2]. The National Highway Traffic Safety Administration (NHTSA) [3] also found that rollover causes a disproportionately large number of serious injuries and fatalities. Over a quarter million rollover car crashes in $2002,21.1 \%$ was fatal. This number is significantly higher than any other types of crashes.

Compared to other types of vehicles, buses have a higher Center of Gravity (CG), and therefore, a higher rate of rollover. According to the Enhanced Coach and Bus Occupant Safety (ECBOS) [4], approximately 35000 people have been injured and 150 killed in nearly 20000 bus and coach crashes. In France, Netherlands, Spain and Sweden, the casualties in buses and coaches are keeping growing. In U.S., rollovers caused approximately $15 \%$ of serious injuries and $20-25 \%$ of fatalities [5].

Therefore, the rollover prevention systems would be important for highway safety. According to recent research [6], it is estimated that about $42 \%$ crashes might have been avoided if the vehicles were equipped with a warning system which could guide drivers to drive buses in an appropriate way before rollover arises. Prevention systems can be categorized as passive warning systems and active control uses a prediction algorithm to evaluate the threat of potential rollover based on the information of vehicle roll angle or lateral acceleration [7]; by contrast, an active control system directly controls the roll motion [8] and yaw motion of the vehicle [9, 10].

Controlling roll or yaw motions is a tough task for in-use vehicles since rollover mitigation hardware usually is not available. On the other hand, a passive warning system only needs a few additional sensors, such as steering wheel angle sensor, accelerometer, and yaw rate sensor, thus it is easier to install a rollover warning system on the large amount of in-use vehicles.

Several studies have been conducted on rollover detection. Rakheja and Pich [11] proposed an early prediction monitor which predicts a rollover whenever measured lateral acceleration or roll angle exceeds the certain threshold values, i.e., when the inner wheel vertical force reaches zero. Preston Thomas and Woodrooffe [12] defined a lateral Load Transfer Ratio (LTR) as the ratio with the vertical load difference and their sum. This ratio is used as a rollover index range from 0 to 1: when the tire vertical loads of 
both sides are equal, LTR is 0; and when the one side tires lift off, LTR is 1. Winkler et al. [13] proposed a Rollover Stability Advisor (RSA) system. RSA is used to predict a rollover acceleration threshold on the real-time measurement of vehicle status. Chen and Peng proposed a Time-To-Rollover (TTR) metric [9], which can predict the time of an impending rollover incident. A real-time vehicle model is used in this metric and future vehicle states can be predicted. Yang and Liu also presented a comprehensive rollover index considering several affecting factors such as vehicle CG position, the energy of rollover, and vertical tire forces [14]. Yoon and Yi developed a rollover index that indicates the danger of vehicle rollover and an index-based rollover mitigation control system using the Vehicle Stability Control (VSC) system already installed on the vehicle [15].

The performance of these rollover detection methodologies highly depends on some key vehicle states and thresholds such as vehicle lateral acceleration [11], vehicle roll angle and rate [12], vehicle vertical loads [1], etc. Among these states, vehicle lateral acceleration is closely related to vehicle roll motion and can be easily measured comparatively. Therefore, vehicle lateral acceleration is usually used in rollover warning systems. Road bank directly impact lateral acceleration. The analysis on how the road bank angle infects the roll stability could been found in literature $[16,17]$, most of the rollover warning algorithms are designed without considering dynamic road bank estimation that vehicles need to face in reality.

Several solutions have been developed to help mitigate the occurrence of rollover crashes [18-22]. Problem locations may have speed reduction signs, rollover warning signs, to pre-warn all drivers of the potential dangerous curve ahead. However, they are negligible for many drivers at most of the time.

Intelligent rollover prevention systems are designed to calculate the rollover potential for a specific vehicle and direct a warning if required. The directed message is achieved by activating a sign or flashing lights only when a potential rollover is detected. However, many drivers are desensitized to a specific warning among all types of flashing lights. It is also difficult for untrained driver to react in time and decrease the vehicle rollover threat. While a rollover warning device based on vehicle velocity is assumed to be easy to understand for most of the driver [23].

This paper presents a real-time rollover trend prediction to indicate bus rollover inclination. The prediction algorithm consists of a dynamic roll stability analysis based on a suspended roll plane model, and a real-time 
warning velocity calculation. A robust parameter estimation algorithm has been developed to estimate road bank and vehicle side slip angle using a dynamic simplex algorithm (DSA). The warning velocity dynamically changes as vehicle is turning or the road bank is varying. The estimated road bank is then used to update the dynamic roll stability analysis, which is the main innovation to the exciting similar algorithms. The estimated vehicle sideslip angle can be utilized to calculate instantaneous vehicle turning radius, which is then used in warning velocity calculation. Since the vehicle velocity is more intuitive than other vehicle states, it is used to assess rollover threat. The driver can easily recognize the maximum stable velocity and thus the rollover threat is mitigated to minimum.

The rest of the paper is organized as follows. The architecture of the proposed algorithm is explained in Section 2, followed by a DSA dynamically estimating road bank and vehicle turning radius in Section 3. Section 4 gives a roll stability analysis based on a suspended vehicle model. A Roll Stability Limit (RSL) that generates a rollover threshold based on lateral acceleration is presented also. In Section 5, velocity margin is employed to inform drivers of rollover risk and the proposed algorithm is evaluated using TruckSim [24] by performing various maneuvers. Section 6 offers some concluding remarks.

\section{Architecture}

A real-time rollover prediction algorithm is developed for evaluating rollover threat of buses and coaches. The proposed algorithm mainly consists of three components as shown in Fig. 1.

Component I-Road Bank Estimation: This component intends to dynamically estimate road bank $\phi_{B}$ and vehicle turning radius $R$. The estimator [6] consists of a 2-DOF non-linear vehicle model and a DSA. Using measured lateral acceleration $a_{y, m}$ and yaw acceleration $\dot{r}_{m}$, road bank is estimated by solving an optimization problem. Then, the dynamically estimated road bank is used to update rollover threshold values; and vehicle sideslip angle is used to calculate the vehicle turning radius by applying a dynamic roll stability analysis. Note that the road friction is assumed a priori known value either directly measured or estimated [25]. Previously study on road friction estimation could also serve as a reference [26].

Component II-Roll Stability Analyses: The most important component is vehicle roll stability analysis. This component applies a suspended roll plane model to determine the roll stability threshold indicated by lateral 


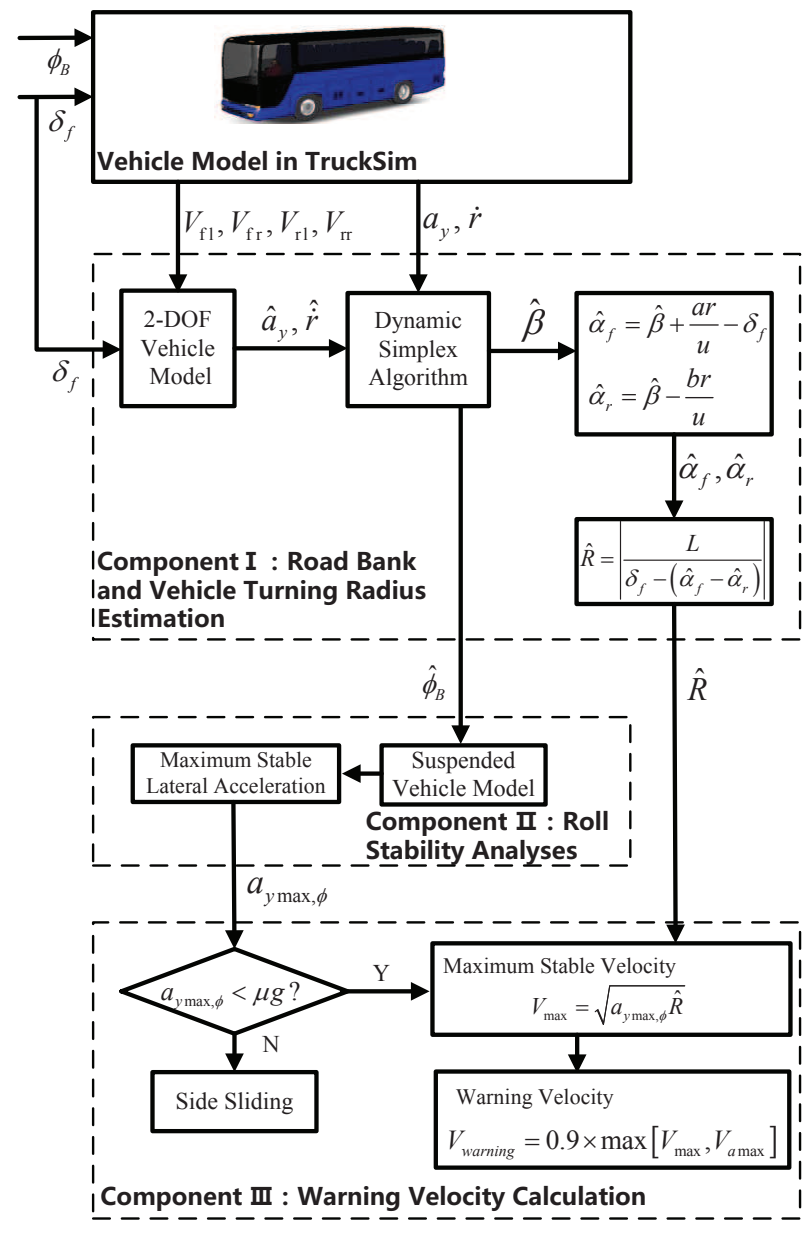

Fig. 1. Block diagram of proposed algorithm

acceleration values. After taking into account the influence of road bank, the maximum stable lateral acceleration $a_{\mathrm{ymax}, \phi}$ is determined to represent the rollover limit.

Component III-Rollover Warning: This component first determines whether a vehicle is at the risk of rollover or lateral side skidding by comparing maximum stable lateral acceleration $a_{\text {ymax }, \phi}$ and the affordable lateral acceleration $\mu g$ under a given tire/road friction condition; then rollover limit $a_{\mathrm{ymax}, \phi}$ is converted to the maximum stable velocity $V_{\max }$ according to instantaneous turning radius, and a warning velocity is calculated with a certain safety margin. 
The TruckSim software is a tool for simulating and analyzing the dynamic behavior of medium to heavy trucks, buses and articulated vehicles. The vehicle model we used for simulation in TruckSim software is a tour bus with two axes.

\section{Road Bank Angles Estimation}

\subsection{Estimation Model}

For estimating road bank angles, a 2-DOF vehicle model [27] with 4 wheel$\mathrm{s}$ needs to be created as in Fig. 2. The model is used for computing lateral acceleration and yaw rate from vehicle states and road friction [28]. Considering road bank angles, equations governing the lateral and yaw motions of a vehicle are as follows:

$$
\begin{gathered}
\mathrm{m}(\dot{v}+r u)=\left(F_{y \mathrm{fl}}+F_{y \mathrm{fr}}\right) \cos \left(\delta_{f}\right)+\left(F_{y \mathrm{rl}}+F_{y \mathrm{rr}}\right)+m g \sin \phi_{B} \\
I_{z} \dot{r}=a\left(F_{y \mathrm{fl}}+F_{y \mathrm{fr}}\right) \cos \left(\delta_{f}\right)-b\left(F_{y \mathrm{r} \mathrm{l}}+F_{y \mathrm{rr}}\right)-\frac{t_{w}}{2}\left(F_{y \mathrm{fl}}-F_{y \mathrm{fr}}\right) \sin \left(\delta_{f}\right) .
\end{gathered}
$$

Note the $V_{G}$ is the vehicle velocity at the CG, which comes from the resultant vector of longitudinal and lateral velocities ( $u$ and $v$ ) respectively. Tire slip angles can be determined according to kinematic relationships as shown in Fig. 2:
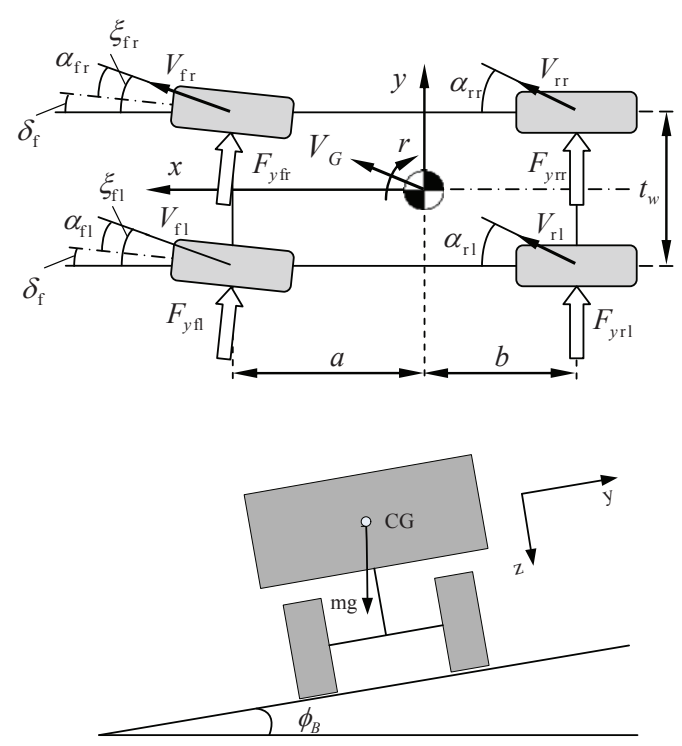

Fig. 2. A 2-DOF vehicle model with four wheels 
Lateral acceleration can be calculated by the following equation:

$$
a_{y}=\dot{v}+u r+g \sin \phi_{B} .
$$

When vehicle is static [29], $\dot{v}$ equals zero at the steady state, the road bank can be estimated from Eq. (3) as follows.

$$
\phi_{B, S}=\sin ^{-1}\left[\left(a_{y}-r u\right) / g\right],
$$

where $\phi_{B, S}$ is called a static road bank angle.

However, the static bank angle does not meet the computation of lateral acceleration in the transient states. Therefore, we present a dynamic simplex method to estimate dynamic road bank and vehicle sideslip angle using the modifications DSA [30]. The flowchart to estimate dynamic road bank using the modifications DSA are shown in Fig. 3.

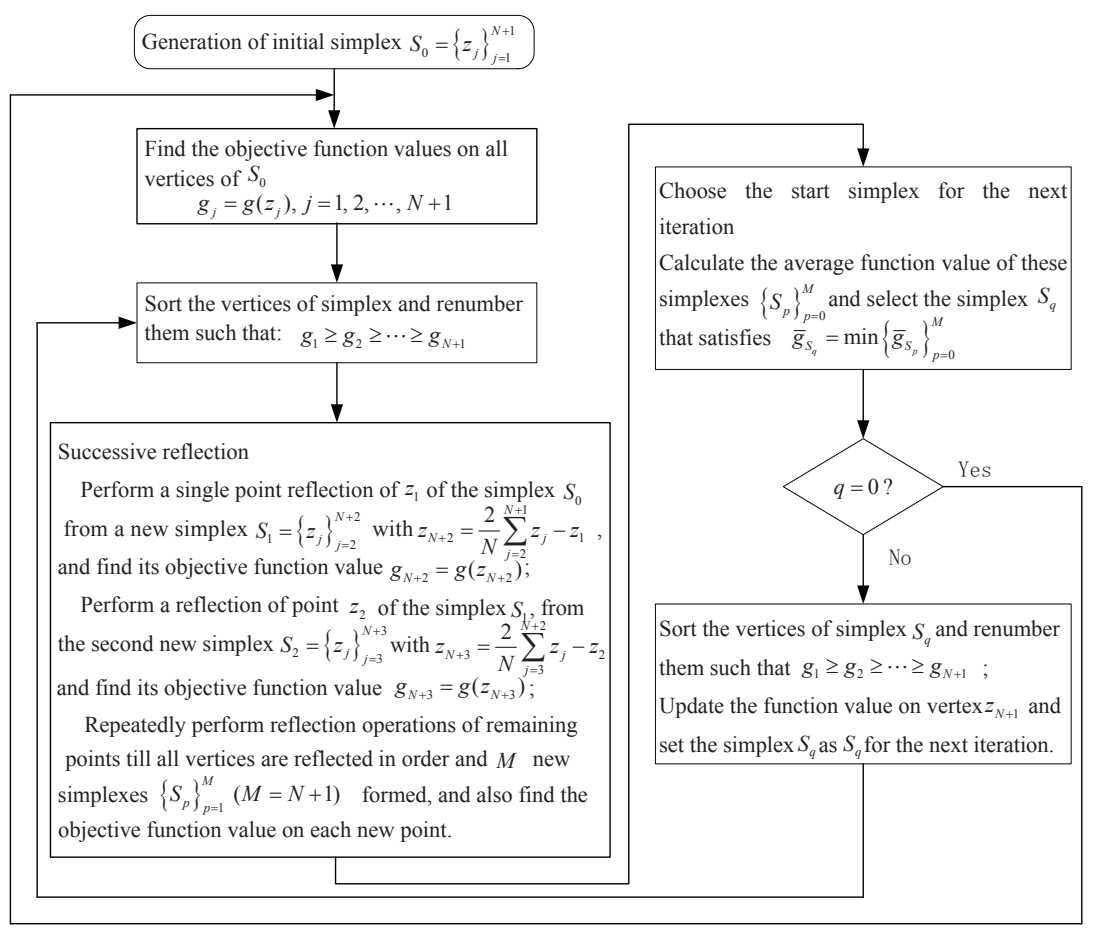

Fig. 3. Flowchart of modified DSA 
The optimization model is as follows:

$$
\left\{\begin{array}{l}
\mathbf{X}=\left[\phi_{B}, \beta\right] \\
\min \quad f(\mathbf{X})=\rho\left(\hat{a}_{y}-a_{y, m}\right)^{2}+\left(\hat{\dot{r}}-\dot{r}_{m}\right)^{2} \\
\text { s.t. } \phi_{B \min } \leq \phi_{B} \leq \phi_{B \max } \\
\quad \beta_{\min } \leq \beta \leq \beta_{\max } .
\end{array}\right.
$$

The penalty functions are given as follows:

$$
\begin{aligned}
& f_{p \phi}=\left\{\begin{array}{cl}
\lambda_{\phi}\left(\phi_{B, \min }-x_{1}\right), & \text { if } x_{1}<-\phi_{B, \max } \\
0, & \text { if }-\phi_{B, \max } \leq x_{1} \leq \phi_{B, \max } \\
\lambda_{\phi}\left(x_{1}-\phi_{B, \max }\right), & \text { if } x_{1}>\phi_{B, \max }
\end{array}\right. \\
& f_{p \beta}=\left\{\begin{array}{cl}
\lambda_{\beta}\left(-\beta_{\max }-\eta x_{2}\right), & \text { if } \eta x_{2}<-\beta_{\max } \\
0, & \text { if }-\beta_{\max } \leq \eta x_{2} \leq \beta_{\max } \\
\lambda_{\beta}\left(\eta x_{2}-\beta_{\max }\right), & \text { if } \eta x_{2}>\beta_{\max }
\end{array}\right.
\end{aligned}
$$

By adding $f_{p \phi}$ and $f_{p \beta}$ to $f(\mathbf{X})$, the final objective function becomes $g(\mathbf{X})=f(\mathbf{X})+f_{p \phi}+f_{p \beta}$, which is an optimization model without constraints.

A trade-off strategy is designed between dynamic response and static accuracy of the estimation for the simplex size selection. The trade-off is large enough to keep up with the moving optimum and does not result in large estimation errors. We carefully tune the simplex size by trial and error.

The estimator parameters are listed in Table 1.

Table 1. Parameters used in DSA

\begin{tabular}{cc|cc}
\hline Parameter & Value & Parameter & Value \\
\hline$l$ & 0.025 & $\lambda_{\phi}$ & 15 \\
$\rho$ & 1.0 & $\phi_{B, \max }$ & 0.45 \\
$\eta$ & 0.75 & $\beta_{\max }$ & 0.2 \\
$\lambda_{\beta}$ & 15 & & \\
\hline
\end{tabular}

\subsection{Estimator Testing}

The road bank angle estimator is evaluated in TruckSim and Matlab packages. A bus model in TruckSim, is equipped with virtual sensors to measure the steering wheel angle, wheel speeds, yaw rate, and lateral acceleration. The simulation is conducted with an ideal driver model. 


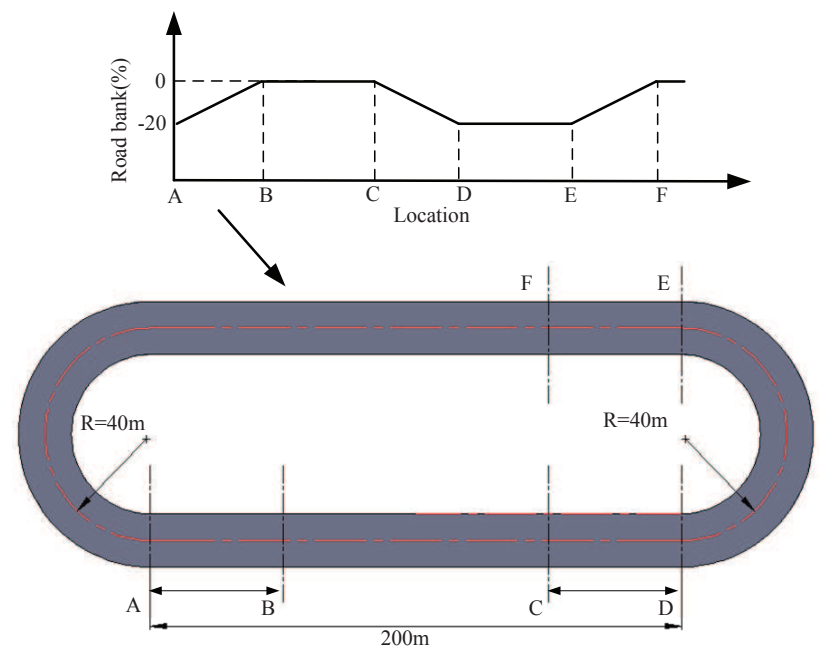

Fig. 4. The virtual ground for tests

As shown in Fig. 4, for verifying the proposed estimator the transien$\mathrm{t}$ maneuvers of a variable banked road are designed and simulated. The TruckSim bus runs counter-clockwise on an oval road with $40 \mathrm{~m}$ radius and $200 \mathrm{~m}$ straight, and the road bank angle is from $-20 \%$ to 0 at the transition areas composed of linear and circular parts. Starting from location A, the initial road bank is $-20 \%$.

\section{a. Maneuver on high friction road}

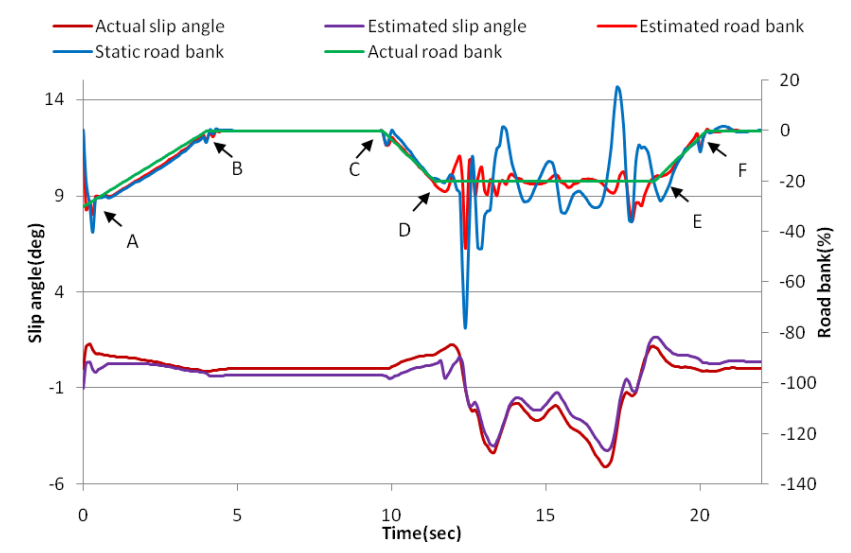

Fig. 5. Estimated results on high friction surface 
In this scenario, the friction coefficient is 0.85 and the target bus speed is $50 \mathrm{~km} / \mathrm{h}$. Estimated results of road bank and vehicle sideslip angle are compared to those measured by the bus model as shown in Fig. 5 .

As shown in Fig. 5, both sideslip angle and road bank varied with transient regions. Comparison of road bank using DSA and static bank angle calculated shows that the static bank angle error is larger when vehicle is turning. While the estimated road bank with DSA is higher accuracy comparatively, and the estimated vehicle sideslip angle matches the actual value.

\section{b. Maneuver on low friction road}

This maneuver is performed on the low friction road surface with a coefficient 0.4 and bus vehicle speed at $30 \mathrm{~km} / \mathrm{h}$. The results are shown in Fig. 6.

In the case, the errors of road bank angle using DSA and static bank angle are less than those on high friction road surface due to the smaller vehicle lateral response. The DSA estimator still has a higher accuracy than static bank angle calculation.

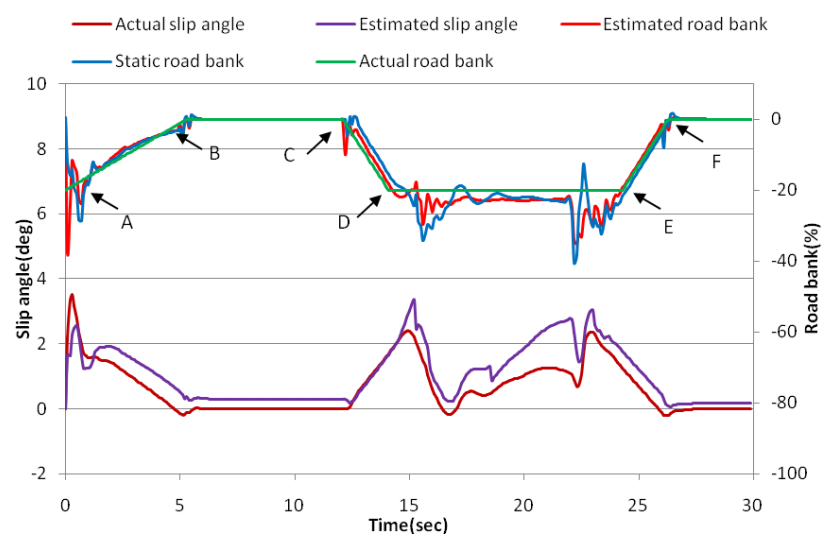

Fig. 6. Estimated results on low friction surface

\section{Roll Stability Analyses}

\subsection{Suspended vehicle model}

Many passive warning systems use a prediction algorithm to determine the threat of impending rollover based on the values of vehicle roll angle and/or lateral acceleration. In order to help measure a vehicles likelihood of rollover, a rollover resistance rating program was proposed by NHTSA, which 


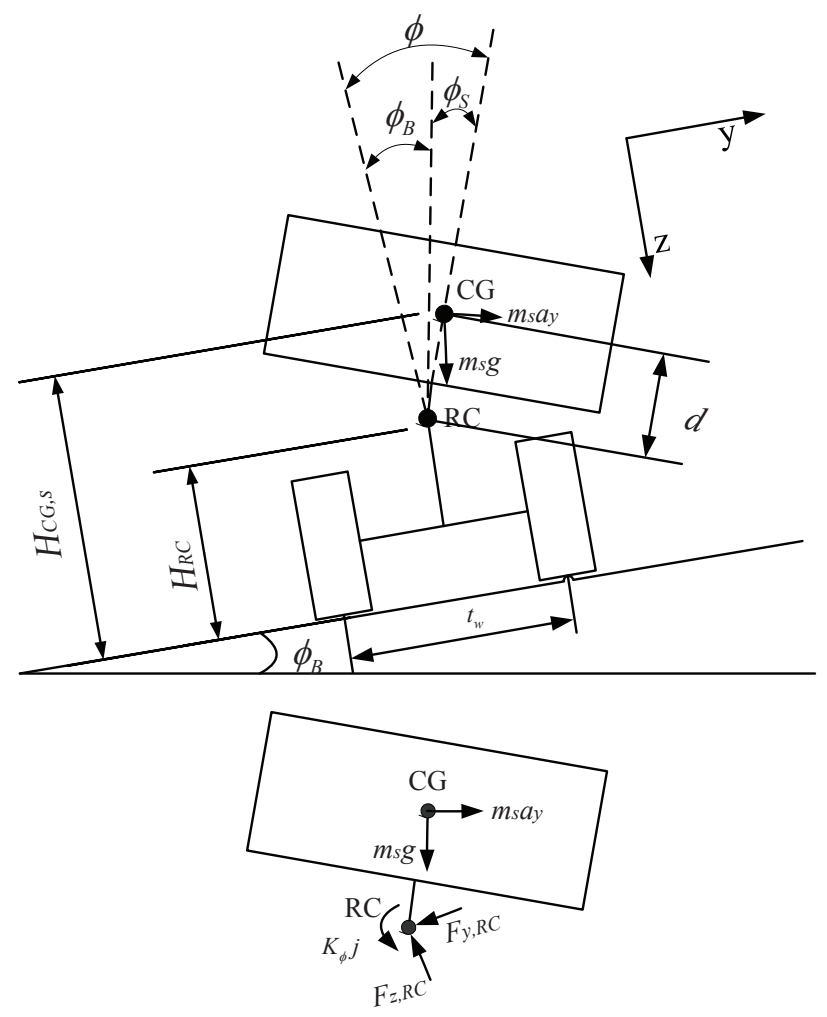

Fig. 7. Schematic representation of suspended vehicle model

uses the Static Stability Factor (SSF), the ratio between a half of the wheel track width and the CG height [31]. If the lateral acceleration exceeds this value, then the system warns an imminent rollover of the vehicle. However, since it does not take into account the effects of suspension deflection, tire compliance, and the dynamics of vehicle control, vehicle rollover may occur at a lower acceleration than the SSF threshold. Thus, it may not provide warning to drivers even when a vehicle rollover happens [32].

Some modifications to the SSF approach have been made to better determine the threshold value and predict vehicle rollovers. These modification$\mathrm{s}$ accurate vehicle roll plan models incorporating the effects of suspension compliance and/or tire compliance [33]. In this section, a suspended vehicle model is introduced for roll stability analysis [34]. 
Equilibrium for the sprung mass can be derived as follows:

$$
\begin{gathered}
\sum F_{y}=F_{y, R C} \cos \phi_{B}+F_{z, R C} \sin \phi_{B}-m_{s} a_{y}=0 \\
\sum F_{z}=-F_{y, R C} \sin \phi_{B}+F_{z, R C} \cos \phi_{B}-m_{s} g=0 \\
\sum M_{R C}=m_{s} a_{y} d \cos \phi_{S}+m_{s} g d \sin \phi_{S}-K_{\phi} \phi=0
\end{gathered}
$$

According to the geometrical relationships shown in Fig. 7, we get

$$
d=\left(H_{C G, s}-H_{R C}\right) / \cos \phi
$$

By assuming small angles, Eqs. (10) and (11) become

$$
K_{\phi} \phi \approx m_{s} a_{y} m+m_{s} g d\left(\phi-\phi_{B}\right)
$$

or

$$
R_{\phi}=\phi /\left[\left(a_{y} / g\right)-\phi_{B}\right] \approx m_{s} g d /\left(K_{\phi}-m_{s} g d\right)
$$

and

$$
d \approx H_{C G, s}-H_{R C}
$$

The above ratio between the sprung mass roll angle and the lateral acceleration in (13) is commonly defined as the vehicle roll gain.

\subsection{Dynamic roll stability limit (RSL)}

A dynamic RSL, which indicates the maximum stable lateral acceleration, is proposed in this study. The proposed RSL changes with road bank.

Summing moments about the outer tire contact point in the roll plane are:

$$
\sum M_{o}=K_{\phi} \phi+F_{y, R C} H_{R C}-F_{z, R C} t_{w} / 2+F_{i, z} t_{w}=0
$$

With the assumption of small angle, Equations (8) and (9) become

$$
\begin{aligned}
& F_{y, R C}=m_{s} a_{y}-m_{s} g \phi_{B} \\
& F_{z, R C}=m_{s} g+m_{s} a_{y} \phi_{B}
\end{aligned}
$$

While the inner wheel lifts off, the vertical force on the inner wheels $F_{i, z}$ turns to zero. So lateral acceleration and roll angle in this case (named $a_{y \max , \phi}$ and $\left.\phi_{\max , \phi}\right)$, yield

$$
K_{\phi} \phi_{\max , \phi}=-\left(m_{s} a_{y \max , \phi}-m_{s} g \phi_{B}\right) H_{R C}+\left(m_{s} g+m_{s} a_{y \max , \phi} \phi_{B}\right) \frac{t_{w}}{2}
$$


Substituting (12) into (18), and using the definition of the roll gain, we have

$$
\frac{a_{y \max , \phi}}{g}=\frac{\phi_{B}\left[H_{C G, s}+\left(H_{C G, s}-H_{R C}\right) R_{\phi}\right]+\left(t_{w} / 2\right)}{H_{C G, s}+\left(H_{C G, s}-H_{R C}\right) R_{\phi}-\phi_{B}\left(t_{w} / 2\right)}
$$

For a rigid vehicle model [35], the roll stability limit is given by the following form:

$$
a_{y \max , \phi} / g=\phi_{B}+t_{w} /\left(2 H_{C G}\right)
$$

If the road bank disturbance is neglected, Equation (17) becomes the form of SSF described by the following

$$
a_{y \max , \phi} / g=t_{w} /\left(2 H_{C G}\right)
$$

\subsection{Simulation results using $R S L$}

For evaluating the proposed RSL, a set of rollover maneuvers (step-steer maneuver, fishhook maneuver and maneuver at dynamic banked road) are conducted in TruckSim.

\section{a. Step-steer maneuver}

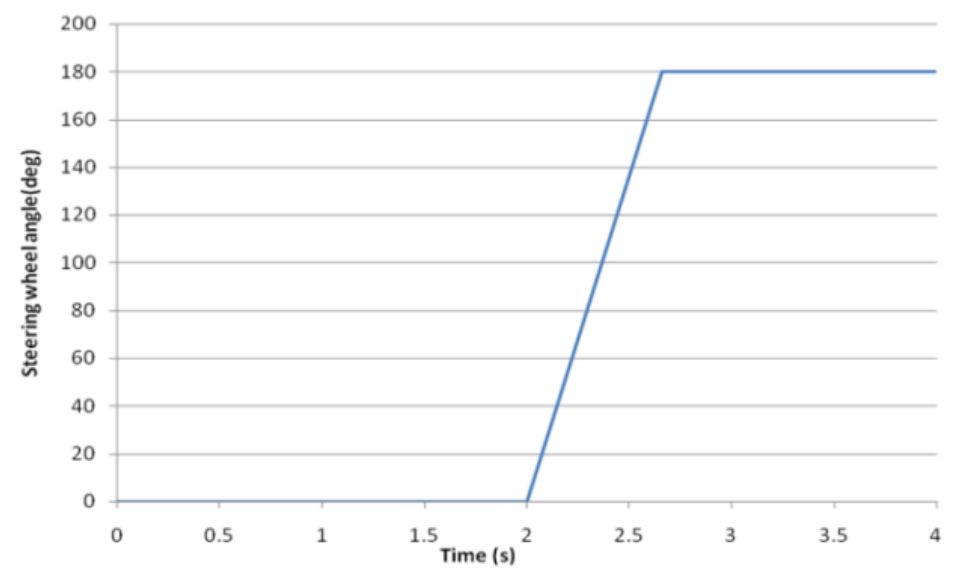

Fig. 8. Steering wheel angle of step-steer

In step-steer maneuver, as shown in Fig. 8, the steering wheel angle and the initial vehicle speed are $180 \mathrm{o}$ and $80 \mathrm{~km} / \mathrm{h}$ respectively. As the vertical force of inner wheel and the lateral acceleration in Fig. 9, a vertical line indicates the moment when the vertical force of the inner wheel turns into zero. From Fig. 9, the vertical force of inner wheel falls down to zero, at the same 


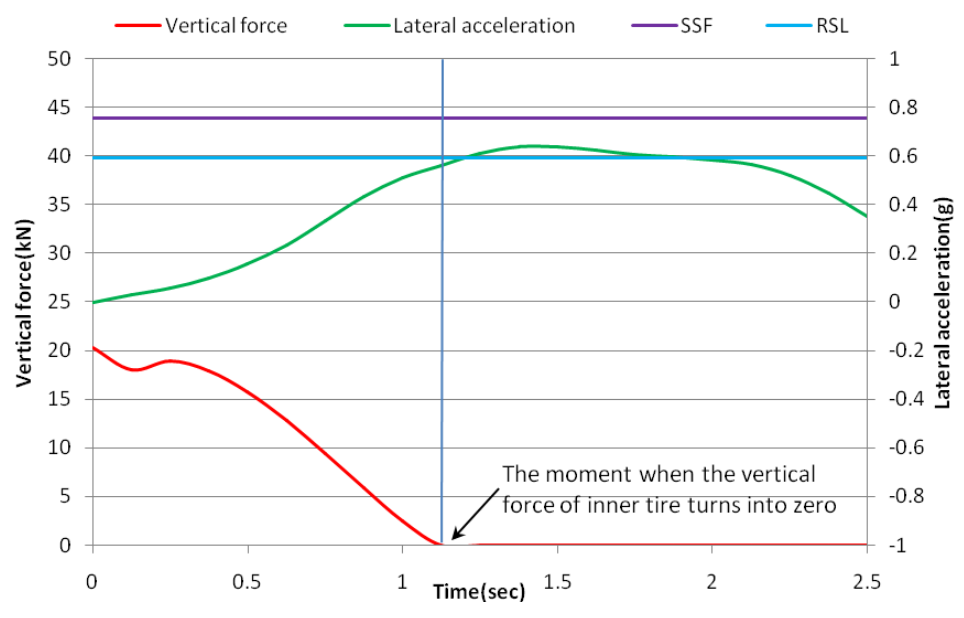

Fig. 9. Step-steer at $80 \mathrm{~km} / \mathrm{h}$

time the lateral acceleration exceeds the value of RSL almost simultaneously. But the value of lateral acceleration is still below the value of SSF threshold, so this could miss a rollover warning.

\section{b. Fishhookmaneuver}

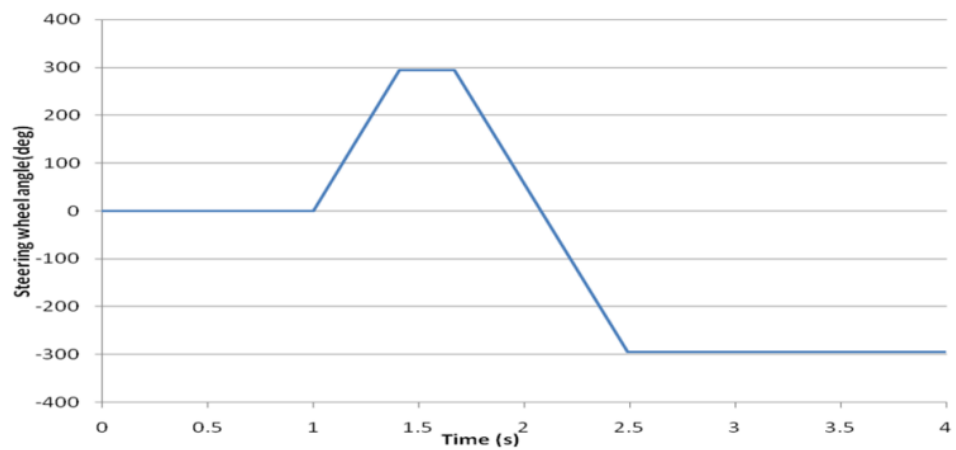

Fig. 10. Steering wheel angle of Fishhook steering

The Fishhook maneuver is one of the standard rollover maneuvers. The maneuver requires the steering wheel angle shown in Fig. 10. The vertical tire forces and the lateral accelerations are showed in Fig. 11. When the vertical force of left front tire becomes zero, the lateral acceleration slightly is over the value of RSL. However, the bus rolls over at the second steering. The vertical force of right front tire is zero at that moment of the lateral 


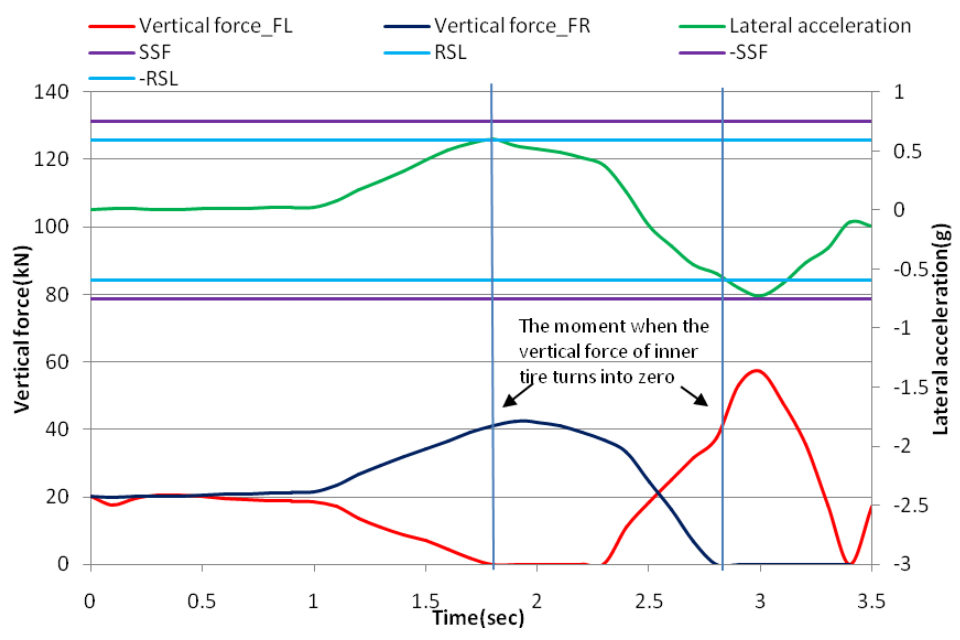

Fig. 11. Fishhook maneuver at $60 \mathrm{~km} / \mathrm{h}$

acceleration over the threshold value.

\section{c. Maneuver on a dynamic banked road}

As shown in Fig. 12, the proposed RSL dynamically changes with road bank on high friction surfaces. A possible false alarm at point A will be avoided due to the raising RSL value as to the estimated bank angle.

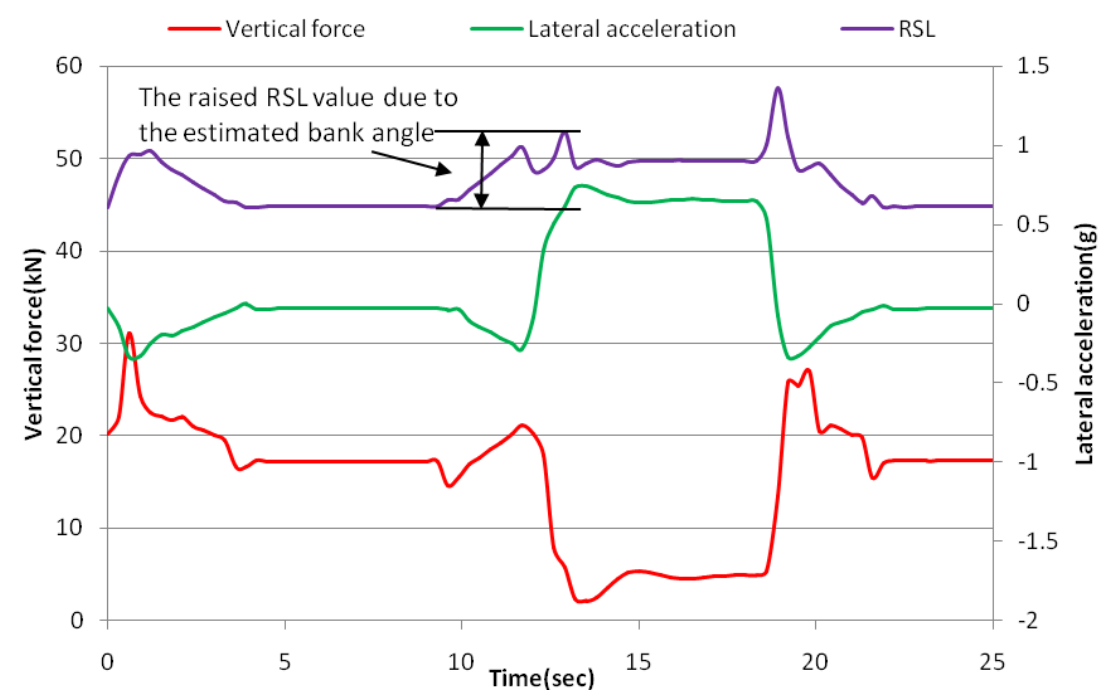

Fig. 12. Maneuver at $50 \mathrm{~km} / \mathrm{h}$ with a variant road bank 


\section{Rollover Warning}

An untrained driver can notice right a specific warning and react quickly to mitigate the vehicle rollover threat with some difficulties. To conquer this, we provide a more intuitive way of driving guidance by converting the calculated RSL to a warning velocity to tell the driver to slow down.

Lateral acceleration will be computed based on turning radius and vehicle speed. If the road curvature is fixed, drivers can not avoid rollover by reducing the steering angle. So, Limiting safe vehicle velocity is a good way to warn drivers of a rollover. As shown in Figure 1, the proposed algorithm compares the current vehicle characteristics with vehicle stability characteristics, which is determined by maximum lateral stable acceleration and tire/road friction.

Based on this comparison, the proposed algorithm first determine whether a vehicle is at risk of rollover or side skidding. If rollover is likely to happen, the proposed algorithm obtains maximum stable velocity for rollover trend analysis.

The proposed algorithm based on the vehicle steering angle, the maximum lateral centrifugal force and tire sideslip angle determines the maximum safety velocity as follows:

$$
V_{\max }=\sqrt{a_{y \max , \phi} \hat{R}}
$$

where the vehicle turning radius $\hat{R}$ is estimated using (24).

Based on the estimated vehicle sideslip angle, the tire slip angle and vehicle turning radius can be calculated according to (23) to (24)

$$
\begin{gathered}
\left\{\begin{array}{l}
\hat{\alpha}_{f}=\hat{\beta}+a r / u-\delta_{f} \\
\hat{\alpha}_{r}=\hat{\beta}-b r / u
\end{array}\right. \\
\hat{R}=\left|L /\left[\delta_{f}-\left(\hat{\alpha}_{f}-\hat{\alpha}_{r}\right)\right]\right|
\end{gathered}
$$

Note that the velocity in Eq. (22) is calculated at the moment when the inner wheels lift off the ground. For warning purpose, a warning velocity threshold should be set. The warning value should be smaller than $V_{\max }$ with a safety margin. Thus, drivers will have enough time to prevent vehicle rollover. The real warning velocity is given by:

$$
V_{\text {warning }}=0.9 \times \min \left(V_{\max }, V_{a \max }\right)
$$


where $V_{a \max }$ is the vehicles maximum velocity.

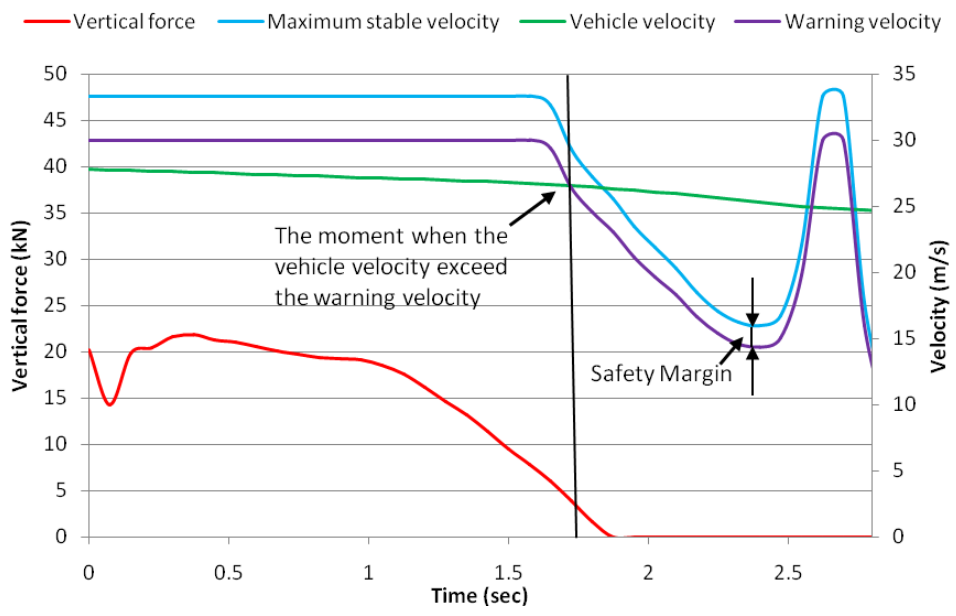

Fig. 13. Step steering at $100 \mathrm{~km} / \mathrm{h}$

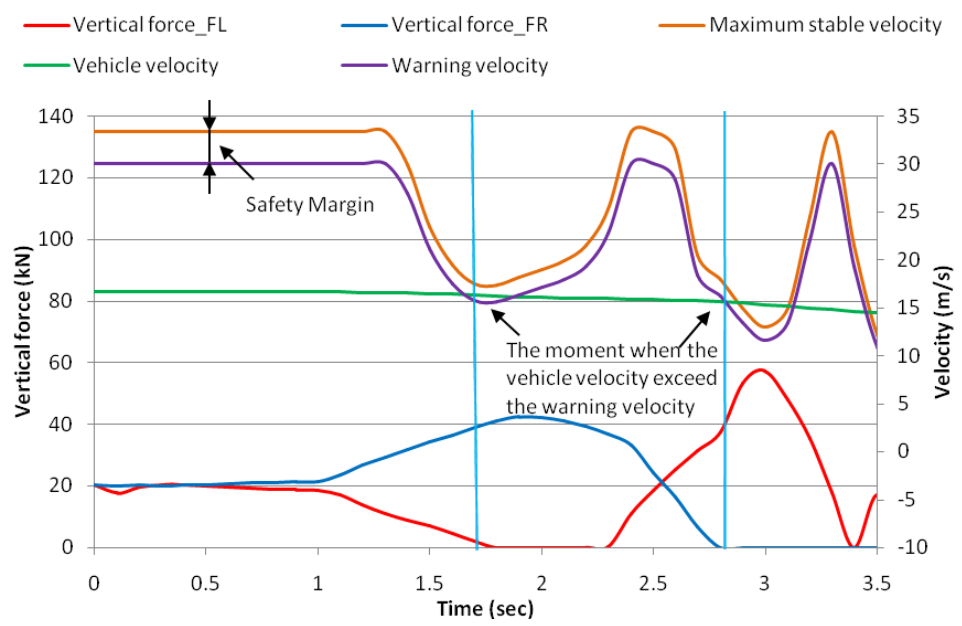

Fig. 14. Fishhook maneuver at $60 \mathrm{~km} / \mathrm{h}$

Figs. 13 and 14 illustrate vertical tire forces, comparison of vehicle velocity, maximum vehicle stable velocity and warning velocity in the step steering scenario and the fishhook steering scenario, respectively. It is shown that maximum vehicle stable velocity varies when steering; and the time when the vehicle velocity exceeds the warning velocity is earlier than the time when the tire lifts off from the ground. 


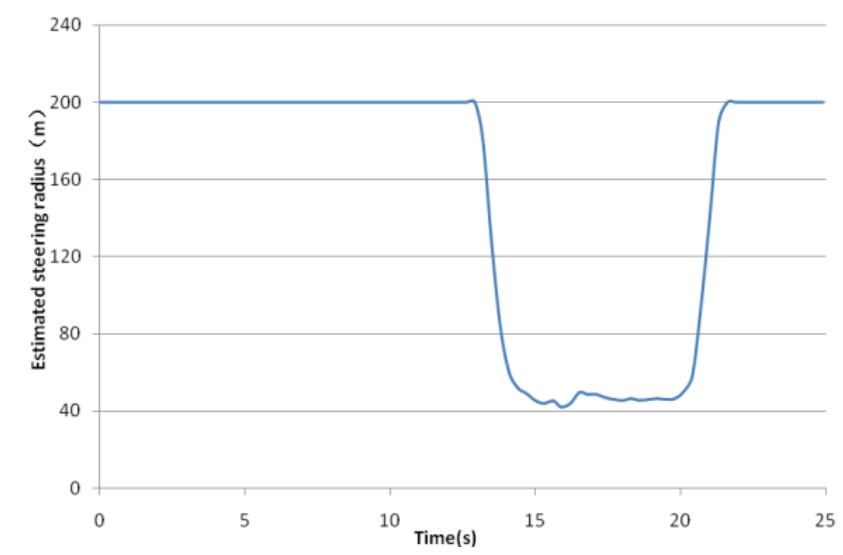

Fig. 15. Estimated steering radius

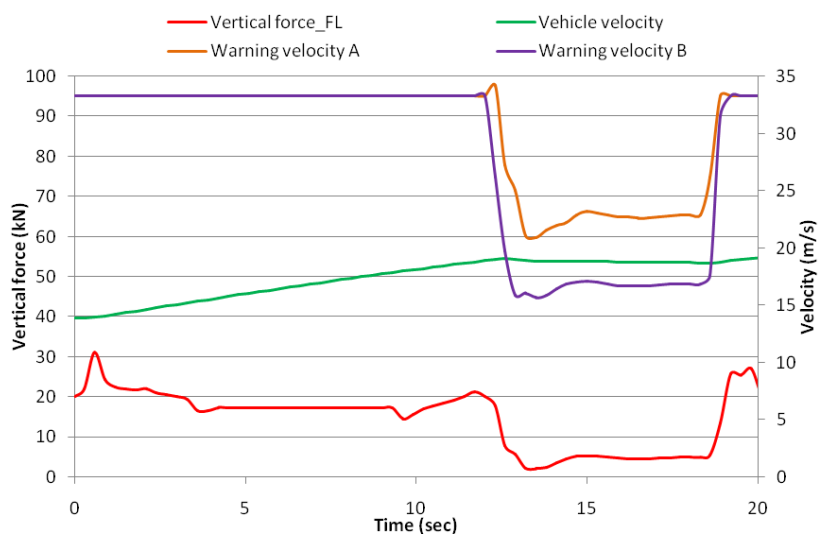

Fig. 16. Maneuver at $50 \mathrm{~km} / \mathrm{h}$ with a variant road bank

The estimated steering radius is shown in Fig. 15. While the vehicle begins turning at around $13 \mathrm{~s}$, the estimated steering radius decreased to about $40 \mathrm{~m}$, which is accorded with the road conditions shown in Fig. 4. It is noted that the turning radius should be infinite while the vehicle runs straightly (from 0 s to $13 \mathrm{~s}$ ). For facilitate comparison, the maximum value of the estimated steering radius shown in the figure is set to $200 \mathrm{~m}$.

As shown in Fig. 16, warning velocities $\mathrm{A}$ and $\mathrm{B}$ are calculated using proposed RSL and the static lateral acceleration threshold, which is calculated based on the static road bank, respectively. Without the consideration of the variant road bank, the vehicle velocity will exceed the warning velocity B 
even when the vertical force of inner wheel does not reach zero. This means the vehicle is still safe and the system mispredicts a rollover. Because RSL will increase when road bank is increasing, the warning velocity A is larger than B. Warning velocity A will therefore give a more accurate prediction of the vehicle rollover.

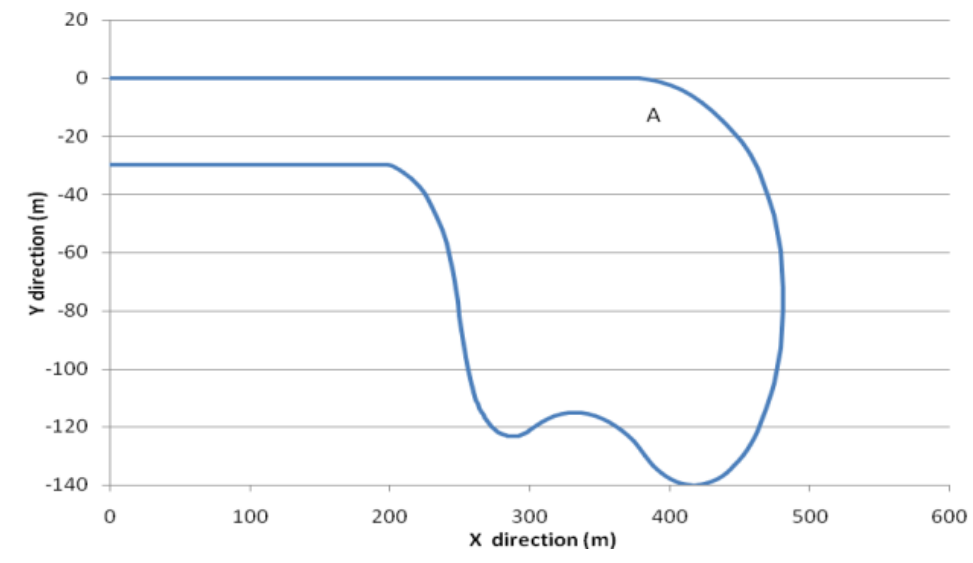

Fig. 17. Test road

The effectiveness of the proposed rollover warning algorithm could be proved by applying braking to slow down the bus after the velocity exceeds the warning velocity. A testing road is shown in Fig. 17. The simulations listed following are performed with driver model in TruckSim software.

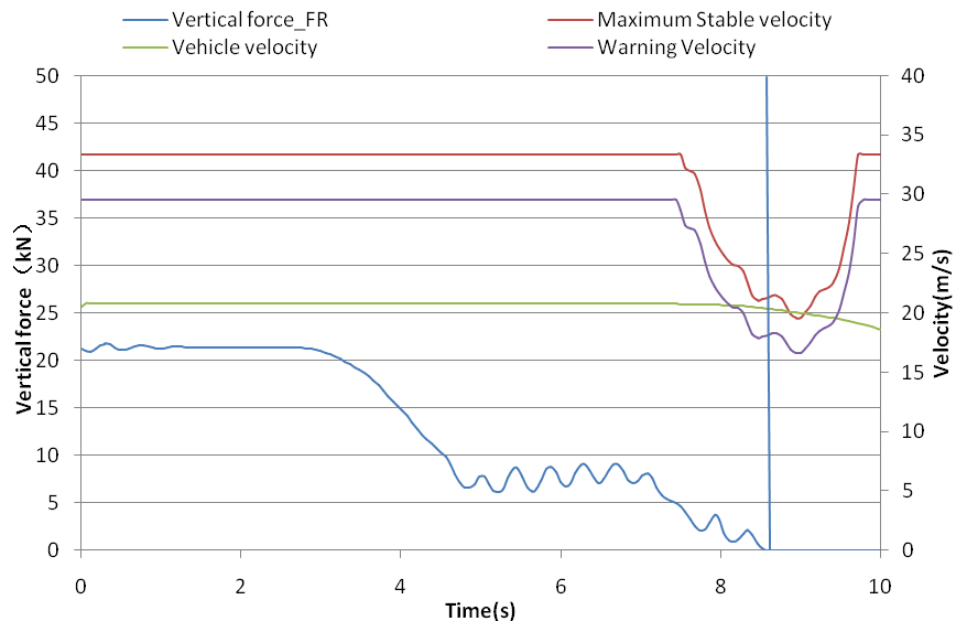

Fig. 18. Maneuver at $75 \mathrm{~km} / \mathrm{h}$ (full load, no breaking) 


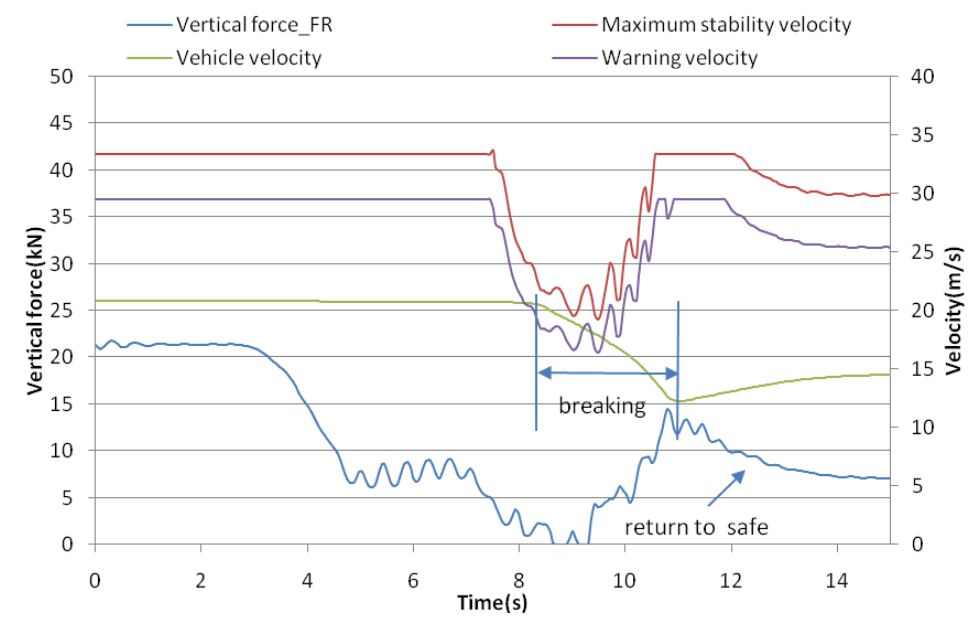

Fig. 19. Maneuver at $75 \mathrm{~km} / \mathrm{h}$ (full load, breaking)

As shown in Figs. 18 and 19, the simulation is evaluated for effectiveness verification with full load, the total mass of the bus is $15000 \mathrm{~kg}$. While the driver breaks the vehicle $0.3 \mathrm{~s}$ after the moment that the vehicle velocity exceed the warning velocity until the velocity is decreased to $0.5 V_{\text {warning }}$, the vehicle could return to safe condition.

For buses, the sprung mass and the C.G. location vary a lot from the empty to full load conditions. A comparing simulation of the warning results of different loads and C.G. position are evaluated as following.

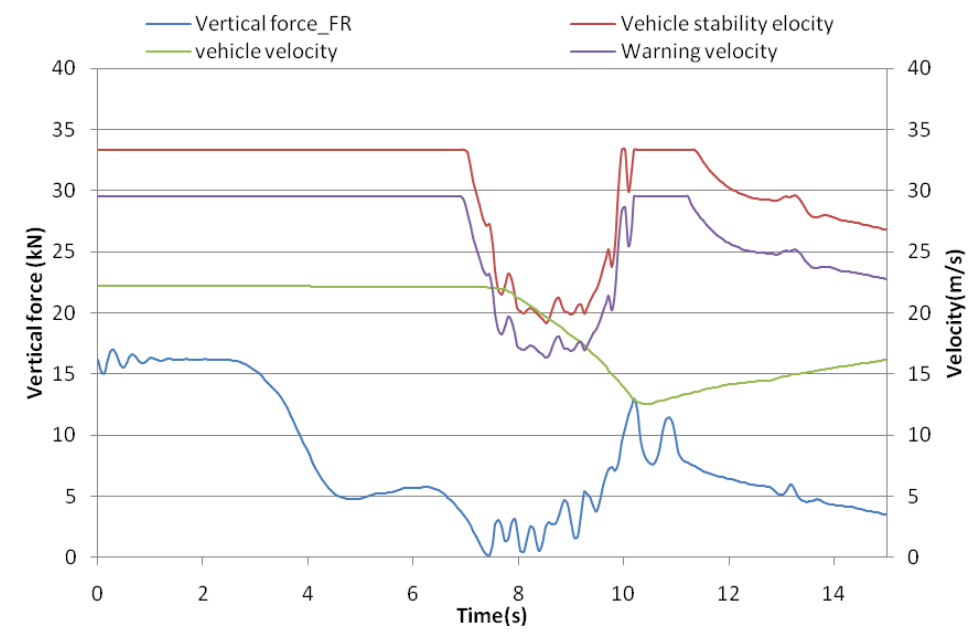

Fig. 20. Maneuver at $80 \mathrm{~km} / \mathrm{h}$ (empty load, breaking) 


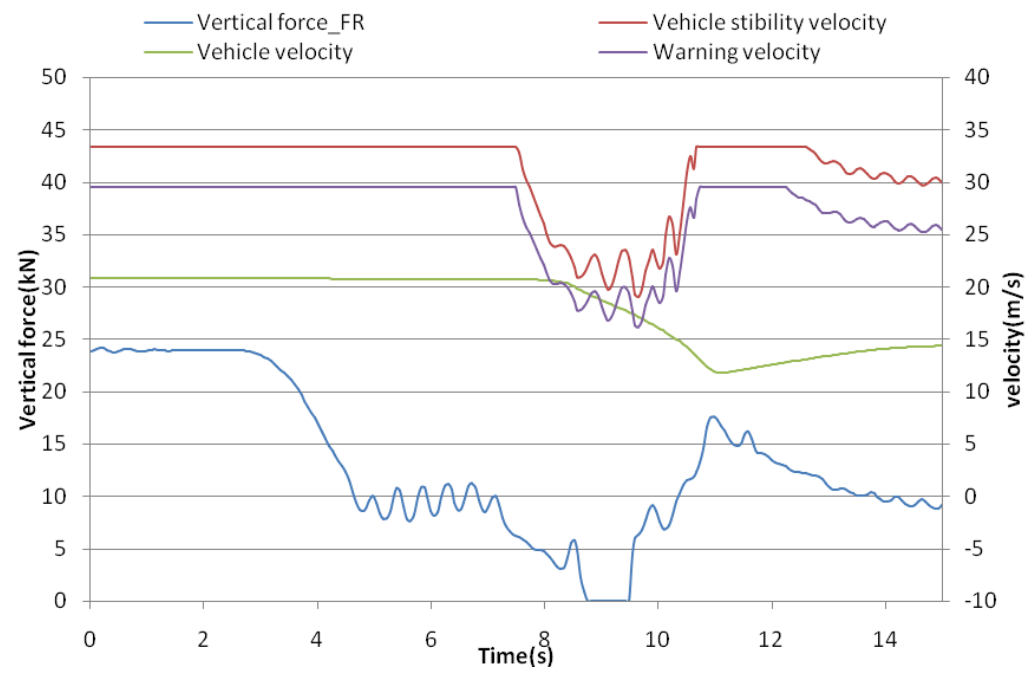

Fig. 21. Maneuver at $80 \mathrm{~km} / \mathrm{h}(0.9 \mathrm{a}$, breaking)

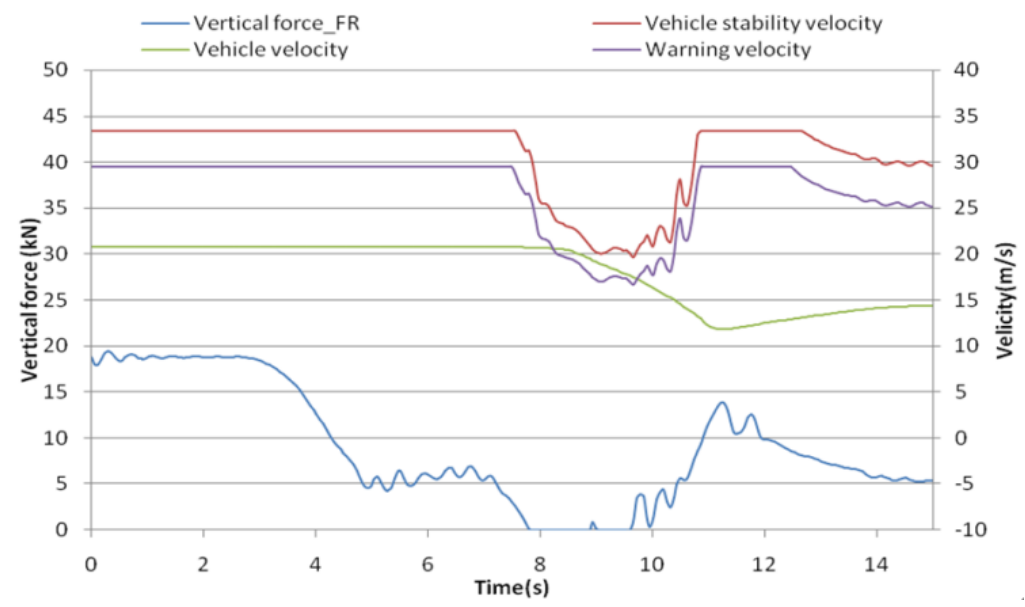

Fig. 22. Maneuver at $80 \mathrm{~km} / \mathrm{h}$ (1.1a, breaking)

As shown in Fig. 20, the simulation is evaluated with empty load and the total mass of the bus is $12000 \mathrm{~kg}$. As shown in Figs. 21 and 22, the distance between vehicle C.G. and front axle are set to $0.9 \mathrm{a}$ and $1.1 \mathrm{a}$, respectively. The results show the robustness to the vehicle load and vehicle C.G. position of the proposed algorithm and the effectiveness of breaking to rollover. 


\section{Conclusion}

In this study, a real-time rollover prediction algorithm has been developed to provide an appropriate prediction of potential rollover. A dynamic road bank and vehicle turning radius estimator using DSA is built firstly, and its performance is evaluated using transient maneuver on a variant banked road in TruckSim software. Simulation results show that the estimated road bank tracks the actual value on both high and low friction road surfaces well, and the estimate of vehicle sideslip angle agrees with its actual value. These estimates are then used in a dynamic roll stability analysis to update rollover threshold values and the warning velocity calculation.

The performance of calculated RSL is compared with SSF by step steer and fishhook maneuver, It is first found that the lateral acceleration exceeds the value of RSL almost simultaneously with the vertical force of inner wheel falls down to zero. It is also shown in simulation that the estimated road bank information is important in roll stability analysis.

The calculated warning velocity is determined using the measurement of lateral acceleration and the estimate of instantaneous vehicle turning radius. It is shown in simulations that the warning velocity provides good performance in predicting the vehicle lift-off from the ground in a variety of vehicle operation conditions.

In its present form, the proposed algorithm can be employed in a real-time rollover prediction for buses. Since the velocity is more intuitive than other vehicle states, the warning information can be easily perceived by divers.

Future work may include the prediction of the proposed algorithm through driver in the loop simulation and road tests.

\section{Acknowledgments}

This research was funded partially by the National Science Foundation of China under Grant \#61371076. The views are those of the authors alone.

\section{Appendix}

Table 2 and Table 3 show the subscripts as well as the variables and parameters used in this paper, respectively. 
Table 2. Subscripts

\begin{tabular}{ll}
\hline Subscripts & Definitions \\
\hline$f$ & Front axle \\
$l$ & Left side of vehicle \\
$r$ & Rear axle or left side of vehicle \\
$f l$ & Front left \\
$f r$ & Front right \\
$r l$ & Rear left \\
$r r$ & Rear right \\
\hline
\end{tabular}

Table 3. Variables and parameters

\begin{tabular}{ll}
\hline Variables & Definitions \\
\hline$a$ & Distance between vehicle COG and front axle \\
$a_{y}$ & Lateral acceleration of vehicle \\
$a_{y \text { max } \phi}$ & Threshold value of lateral acceleration at wheel lift off \\
$a_{y, m}$ & Measured lateral acceleration \\
$b$ & Distance between vehicle COG and rear axle \\
$d$ & Distance from COG of sprung mass to roll axis \\
$f$ & Objective function of optimization \\
$f_{p \beta}$ & Penalty function for constraint of sideslip angle \\
$f_{p \phi}$ & Penalty function for constraint of road bank \\
$F_{y}$ & Lateral tire force in tire y-axis(of wheel plane) \\
$F_{z}$ & Vertical force on tire \\
$F_{i, z}$ & Vertical force on the inner wheel \\
$g$ & Objective function with penalty functions added; acceleration of gravity \\
$h_{\phi}$ & COG height of sprung mass respect to roll axis \\
$H_{R C}$ & Height of roll axis respect to grand \\
$H_{C G, s}$ & COG height of sprung mass respect to grand \\
$I_{z}$ & Yaw moment of inertia (about vehicle z-axis) \\
$K_{\phi}$ & Roll stiffness of suspension \\
$L$ & Wheel base, $L=a+b$ \\
$m$ & Total vehicle mass \\
$m_{s}$ & Spung mass \\
$N$ & Dimension of the DSA space \\
$r$ & Yaw rate
\end{tabular}


Table 3. Variables and parameters

\begin{tabular}{ll}
\hline Variables & Definitions \\
\hline$R_{w}$ & Wheel radius \\
$R_{\phi}$ & Roll gain \\
$S$ & Simplex \\
$t_{w}$ & Wheel track \\
$\mu$ & Longitudinal speed \\
$v$ & Lateral speed \\
$V$ & Wheel speed \\
$V_{G}$ & Velocity vector at vehicle COG \\
$V_{\max }$ & Maximum stable vehicle velocity \\
$z$ & Vertex of simplex \\
$\alpha$ & Tire sideslip angle \\
$\beta$ & Vehicle sideslip angle at COG \\
$\delta_{\mathrm{f}}$ & Steer angle at front wheels \\
$\phi$ & Vehicle roll angle \\
$\phi_{\max , \phi}$ & Threshold value of roll angle at wheel lift off \\
$\phi_{B}$ & Road bank angle \\
$\phi_{B, S}$ & Static road bank angle \\
$\phi_{S}$ & Sprung mass roll angle \\
$\eta$ & Scale for vehicle sideslip angle at COG \\
$\lambda_{i}$ & Coefficients for penalty functions $(i=\phi, \beta)$ \\
$\mu$ & Tire/road friction coefficient \\
$\rho$ & Weight for lateral acceleration in optimization model \\
\hline
\end{tabular}

\section{Reference}

[1] National Highway Traffic Safety Administration, Initiative to address the mitigation of vehicle rollover,, Tech. rep., Docket No. NHTSA-200314622-1 (2003).

[2] G. J. Forkeenbrock, W. R. Garrott, M. Heitz, B. C. O'Harra, An experimental examination of $\mathrm{j}$-turn and fishhook maneuvers that may induce on-road, untripped, light vehicle rollover, Tech. rep., SAE Technical Paper, No. 2003-01-1008 (2003).

[3] National Highway Traffic Safety Administration, Motor vehicle traffic 
crash injury and fatality estimates, 2002 early assessment, Tech. rep. (2003).

[4] European Conmmission, White paper-European transport policy for 2010: time to decide, Office for Official Publications of the European Communities, Luxembour, 2001.

[5] National Highway Traffic Safety Administration, Traffic safety facts 1998: a compilation of motor vehicle crash data from the fatality analysis reporting system and the general estimates system, Tech. rep. (1999).

[6] G. Yu, D. Wang, Q. Li, P. Wang, Y. Wang, Road bank estimation for bus rollover prediction, Applied Mathematics \& Information Sciences 7 (5) (2013) 2027-2034.

[7] R. Goldman, M. El-Gindy, B. Kulakowski, Rollover dynamics of road vehicles: Literature survey, International Journal of Heavy Vehicle Systems 8 (2) (2001) 103-141.

[8] B. C. Chen, W. F. Hsu, Sliding-mode control design of electric stability control for rollover prevention, in: Proceedings of the AVEC2008, Ninth international symposium on advanced vehicle control, 2008, pp. 714-720.

[9] B. C. Chen, H. Peng, Differential-braking-based rollover prevention for sport utility vehicles with human-in-the-loop evaluations, Vehicle System Dynamics 36 (4-5) (2001) 359-389.

[10] T. J. Wielenga, M. A. Chace, A study in rollover prevention using antirollover braking, Tech. rep., SAE Technical Paper, No. 2000-01-1642 (2000).

[11] S. Rakheja, A. Piche, Development of directional stability criteria for an early warning safety device, Tech. rep., SAE Technical Paper, No. 902265 (1990).

[12] J. Preston-Thomas, J. Woodrooffe, FA feasibility study of a rollover warning device for heavy trucks, 1990.

[13] C. Winkler, Cooperative agreement to foster the deployment of a heavy vehicle intelligent dynamic stability enhancement system, Tech. rep. (1998). 
[14] H. Yang, L. Y. Liu, A robust active suspension controller with rollover prevention, Tech. rep., SAE Transaction, no.2003-01-0959 (2003).

[15] J. Yoon, D. Kim, K. Yi, Design of a rollover index-based vehicle stability control scheme, Vehicle system dynamics 45 (5) (2007) 459-475.

[16] M. Doumiati, A. C. Victorino, A. Charara, D. Lechner, Onboard realtime estimation of vehicle lateral tire-road forces and sideslip angle, Mechatronics, IEEE/ASME Transactions on 16 (4) (2011) 601-614.

[17] R. Rajamani, D. Piyabongkarn, V. Tsourapas, J. Y. Lew, Parameter and state estimation in vehicle roll dynamics, Intelligent Transportation Systems, IEEE Transactions on 12 (4) (2011) 1558-1567.

[18] R. Rajamani, D. Piyabongkarn, New paradigms for the integration of yaw stability and rollover prevention functions in vehicle stability control, Intelligent Transportation Systems, IEEE Transactions on 14 (1) (2013) 249-261.

[19] G. Phanomchoeng, R. Rajamani, Real-time estimation of rollover index for tripped rollovers with a novel unknown input nonlinear observer, Mechatronics, IEEE/ASME Transactions on 19 (2) (2014) 743-754.

[20] C. Larish, D. Piyabongkarn, V. Tsourapas, R. Rajamani, A new predictive lateral load transfer ratio for rollover prevention systems, Vehicular Technology, IEEE Transactions on 62 (7) (2013) 2928-2936.

[21] S. Solmaz, Switched stable control design methodology applied to vehicle rollover prevention based on switched suspension settings, Control Theory \& Applications, IET 5 (9) (2011) 1104-1112.

[22] H. Imine, L. M. Fridman, T. Madani, Steering control for rollover avoidance of heavy vehicles, Vehicular Technology, IEEE Transactions on 61 (8) (2012) 3499-3509.

[23] H. Gharavi, S. Gao, 3-d motion estimation using range data, Intelligent Transportation Systems, IEEE Transactions on 8 (1) (2007) 133-143.

[24] Mechanical Simulation Corp, Trucksim software. 
[25] C. Sierra, E. Tseng, A. Jain, H. Peng, Cornering stiffness estimation based on vehicle lateral dynamics, Vehicle System Dynamics 44 (sup1) (2006) 24-38.

[26] N. Ding, S. Taheri, Application of recursive least square algorithm on estimation of vehicle sideslip angle and road friction, Mathematical problems in engineering 2010.

[27] H. B. Pacejka, Tyre and vehicle dynamics, Butterworth-Heinemann Woburn, MA, USA, 2002.

[28] N. Ding, S. Taheri, A modified dugoff tire model for combined-slip forces, Tire Science and Technology 38 (3) (2010) 228-244.

[29] H. E. Tseng, B. Ashrafi, D. Madau, T. A. Brown, D. Recker, The development of vehicle stability control at ford: Focused section on mechatronics in automotive systems, IEEE/ASME transactions on mechatronics 4 (3) (1999) 223-234.

[30] Q. Xiong, A. Jutan, Continuous optimization using a dynamic simplex method, Chemical Engineering Science 58 (16) (2003) 3817-3828.

[31] J. Yoon, W. Cho, J. Kang, B. Koo, K. Yi, Design and evaluation of a unified chassis control system for rollover prevention and vehicle stability improvement on a virtual test track, Control Engineering Practice 18 (6) (2010) 585-597.

[32] J. Jung, T. Shim, J. Gertsch, A vehicle roll-stability indicator incorporating roll-center movements, Vehicular Technology, IEEE Transactions on 58 (8) (2009) 4078-4087.

[33] S. Takano, M. Nagai, Dynamics control of large vehicles for rollover prevention, in: Proceedings of the IEEE International, Vehicle Electronics Conference, IEEE, 2001, pp. 85-89.

[34] J. Gertsch, T. Shim, Interpretation of roll plane stability models, International journal of vehicle design 46 (1) (2008) 72-93.

[35] J. Bernard, J. Shannan, M. Vanderploeg, Vehicle rollover on smooth surfaces, Tech. Rep. 891991, SAE Technical Paper, No. 891991 (1989). 